\title{
EFEITO DA ÉPOCA DE COLHEITA E DA ESPESSURA DO TEGUMENTO SOBRE A VIABILIDADE E O VIGOR DE SEMENTES DE SOJA ${ }^{1}$
}

\author{
MARIA IZABEL KRÜGER GIURIZATTO ${ }^{2}$ \\ LUIZ CARLOS FERREIRA DE SOUZA ${ }^{3}$ \\ ANTÔNIO DIAS ROBAINA ${ }^{3}$ \\ MANOEL CARLOS GONÇALVES ${ }^{3}$
}

germinação e de tetrazólio e o vigor, pelos testes de emergência em areia, teste de tetrazólio e pelo envelhecimento acelerado. As sementes das linhagens BRD9561 (tegumento preto), BRD-9527 (tegumento marrom), BRD-9502 e BRD-9507 (tegumento amarelo) apresentam maior espessura de tegumento, mas a espessura não é uma característica que per si assegura melhor qualidade fisiológica das sementes, independente da época de colheita. O retardamento de colheita reduziu a germinação e o vigor das sementes e ainda aumentou a porcentagem de embebição de água pelas sementes.

TERMOS PARA INDEXAÇÃO: Sementes de soja, espessura de tegumento, retardamento de colheita, viabilidade das sementes, vigor das sementes.

\section{EFFECTS OF HARVEST EPOCH AND SEED COAT THICKNESS ON VIABILITY AND VIGOR OF SOYBEAN SEEDS}

\begin{abstract}
The research was conducted at the Núcleo Experimental de Ciências Agrárias of the Federal University of Mato Grosso do Sul(UFMS), in Dourados, MS. The objectives were to evaluate seed viability and vigor of nine soybean genotypes (five cultivars: EMBRAPA-64, EMBRAPA-4, BR-16, FTAbyara, and IAC-100; and four lines: BRD-9527, BRD-9651, BRD-9507, and BRD-9502), with different seed coat colors and coat tickness, harvested at stage R8 and 14 days later. After harvest, seed coat thickness
\end{abstract}

and water uptake (\%) was determined. Seed viability was evaluated trough germination and tetrazolium tests, and seed vigor was evaluated through emergence in sand, tetrazolium and through accelerated aging tests. Lines BRD-9561 (black coat), BRD-9527 (brown coat), BRD-9507 and BRD-9502 (yellow) had thicker teguments, but this characteristic per se does not guarantee greater plant vigor and viability. Delaying harvest resulted in low seed vigor and viability and increased imbibitions percentage in water.

INDEX TERMS: Soybean seed, coat thickness, harvest delaying, seed vigor and viability.

1. Extraído da dissertação apresentada pelo primeiro autor para obtenção do título de Mestre pela Universidade Federal de Mato Grosso do Sul (UFMS).

2. Engenheiro Agrônomo, MSc., Agência Estadual de Defesa Sanitária Animal e Vegetal de Mato Grosso do Sul, Rua Iguaçu, 995, Jdim Girassol - 79824-180, Dourados, MS, m.kruger@terra.com.br.

3. Engenheiro Agrônomo, Dr., Professor Adjunto da Universidade Federal de Mato Grosso do Sul, Caixa Postal 533, 79804-970, Dourados, MS. 


\section{INTRODUÇÃO}

A baixa qualidade fisiológica das sementes de soja, produzidas em quase todas as áreas situadas ao norte do paralelo $24^{\circ} \mathrm{LS}$, tem se constituído num dos principais problemas para produção de sementes nessas regiões. Para esses locais, onde as oscilações ambientes determinam a qualidade final da semente, atenção especial deve ser dada aos meios disponíveis de preservar a qualidade das sementes expostas às condições adversas de campo e armazenamento (Tavares et al., 1987).

Na região sul do Mato Grosso do Sul há dificuldades de se produzir sementes de boa qualidade, principalmente para as cultivares precoces, devido à ocorrência de chuvas no período próximo da colheita. Conforme Costa et al. (1995), no estádio de maturidade fisiológica, a semente apresenta o máximo de germinação e de vigor, mas devido ao alto teor de água das sementes e vagens, a colheita fica impossibilitada.

A fase compreendida entre a maturidade fisiológica e a colheita pode ser considerada como um período de armazenamento em campo, durante o qual as condições climáticas raramente são favoráveis, fazendo com que se inicie o processo de deterioração das sementes. Segundo Sediyama et al. (1981), a colheita das sementes de soja deve ser feita de preferência logo após a maturidade fisiológica. Entretanto, nem sempre essa exigência pode ser satisfeita, principalmente se a colheita coincidir com períodos chuvosos, que podem causar danos irreparáveis à qualidade das sementes, influenciando a capacidade germinativa e o seu valor comercial.

Em condições climáticas favoráveis, os problemas podem não se manifestar; porém, a ocorrência de chuvas ou orvalho, associada a altas temperaturas diminuem a qualidade das sementes, à medida que a colheita é retardada. O retardamento da colheita prejudica os fatores de qualidade, como o brilho, vigor, germinação e reduz a densidade das sementes, pelo aumento da taxa de respiração das mesmas (Vieira et al., 1981).

Linhagens de soja com tegumento duro tendem a embeber água mais lentamente que outras, sendo mais resistentes às flutuações de umidade e protegidas da deterioração no campo (Horlings et al., 1991). As linhagens de soja com tegumento de coloração preta são mais resistentes às intempéries do campo, provavelmente por terem um tegumento mais espesso que as linhagens de tegumento amarelo (Dassou e Kueneman, 1984). Segundo Peske e Pereira (1983), sementes com tegumento preto embebem água a uma velocidade menor, quando comparadas com as amarelas, não sendo, portanto, tão prejudicadas pelas condições ambientais na fase de pré-colheita.

O efeito regulador do tegumento sobre a difusão de água tem sido estudado por vários pesquisadores, mas o mecanismo que restringe a absorção de água pela semente de soja ainda não foi completamente determinado. Resultados de estudos anatômicos e histológicos mostraram a presença de substâncias impermeáveis à água, formadas em alguma camada do tegumento das sementes duras de soja. De acordo com Arantes et al. (1994), o caráter dureza do tegumento é conferido pela camada de suberina localizada na camada interna das células paliçádicas sob a região do hilo, sendo essa camada contínua em sementes impermeáveis e descontínua em sementes permeáveis.

A ocorrência de diferenças no grau de permeabilidade do tegumento levou pesquisadores a determinarem a possível ocorrência de materiais hidrófobos na camada paliçádica, e em tegumento permeável, foi demonstrada a existência de lipídios que se distribuem por toda a camada paliçádica, ao passo que em sementes duras, esses componentes apresentaram-se em grande quantidade na base das células e penetrando entre as paredes celulares (Peske et al., 1983).

Também foi observado por França Neto et al. (1999) maior conteúdo percentual de lignina nos tegumentos de linhagens com sementes de coloração escura $(12,18 \%)$, ao passo que as linhagens de tegumento amarelo apresentaram $4,75 \%$, conferindo uma maior qualidade nas sementes com maior conteúdo de lignina.

Com este trabalho objetivou-se avaliar a qualidade fisiológica das sementes de nove genótipos de soja, com diferentes colorações e espessuras de tegumento, colhidas na maturidade fisiológica e com 14 dias após esse estádio.

\section{MATERIAL E MÉTODOS}

O trabalho foi conduzido no Núcleo Experimental de Ciências Agrárias, da Universidade Federal do Mato Grosso do Sul, em Dourados-MS, situado em $22^{\circ} 14^{\prime}$ de latitude sul, $54^{\circ} 44^{\prime}$ de longitude oeste e altitude de $452 \mathrm{~m}$, no ano agrícola 1996/97.

As sementes de nove genótipos de soja avaliadas nesta pesquisa foram oriundas de experimento de campo, dos quais, cinco cultivares: Embrapa-64, Embrapa4, BR-16, FT-Abyara e IAC-100 (com tegumento de coloração amarela) e quatro linhagens: BRD-9561 (tegumento preto), BRD-9527 (tegumento marrom), BRD9502 e BRD-9507 (tegumento amarelo), foram colhidos na maturidade fisiológica (estádio R8) e com quatorze

Ciênc. agrotec., Lavras. V.27, n.4, p.771-779, jul./ago., 2003 
dias de retardamento de colheita. No Quadro 1, está apresentada a relação dos genótipos avaliados, com as respectivas cores de tegumento das sementes e as datas de semeadura e de colheita dessas.

Após a colheita manual e a trilhagem com trilhadeira estacionária, as sementes foram levadas para o laboratório de análise de sementes, onde se determinaram a espessura de tegumento, a porcentagem de embebição de água pelas sementes, a germinação das sementes pelo teste de germinação e de tetrazólio, e o vigor das sementes pelo teste de tetrazólio, emergência em areia e envelhecimento acelerado.

Para a determinação da espessura do tegumento, quatro sementes de cada genótipo foram embebidas em glicerina pura para o amolecimento dos tecidos esclereificados, por 5 a 10 minutos, e realizados cortes na altura do hilo da semente com uma espessura aproximada de 30 micrômetros $(\mu \mathrm{m})$ utilizando-se um micrótomo de mesa. Montaram-se lâminas semipermanentes com glicerina a $50 \%$, vedadas com esmalte incolor e foram medidos 10 campos com o uso de um tambor micrométrico acoplado a um microscópio e a medida foi expressa em micrômetros $(\mu \mathrm{m})$.

O potencial de viabilidade e o vigor das sementes avaliados pelo teste de tetrazólio foram determinados com quatro repetições de 50 sementes para cada tratamento. As sementes pré-acondicionadas em papel úmido por um período de 16 horas foram imersas em solução $0,075 \%$ de 2,3,5- trifenil cloreto de tetrazólio, sendo, então, mantidas em estufa a $36^{\circ} \mathrm{C}$ por três horas para a coloração. Em seguida, foram lavadas e avaliadas individualmente, conforme França Neto et al. (1994).

O teste de emergência em areia foi instalado em condições de casa-de-vegetação, sendo a areia anteriormente lavada e esterilizada com brometo de metila, colocada em bandejas plásticas e irrigada por dois dias consecutivos para melhor acomodação do leito. Foram utilizadas quatro repetições de 100 sementes por tratamento, semeadas em sulcos longitudinais com três $\mathrm{cm}$ de profundidade e espaçadas $4 \mathrm{~cm}$ entre si. A umidade foi mantida com irrigações leves, e dez dias após a semeadura, as plântulas foram avaliadas e o resultado, expresso em porcentagem de plântulas normais.

A metodologia adotada para o teste de envelhecimento acelerado foi a descrita por Marcos Filho et al. (1987), utilizando-se uma minicâmara na qual foram colocadas 240 sementes de cada tratamento sobre uma tela localizada a $2 \mathrm{~cm}$ do fundo do gerbox, adicionando-se $40 \mathrm{ml}$ de água no seu interior. A seguir, foram le- vadas para a câmara de envelhecimento acelerado regulada a uma temperatura de $41^{\circ} \mathrm{C}$ e em torno de $95 \%$ de umidade relativa, por um período de 48 horas. Retiradas da câmara, as sementes foram colocadas para germinar em rolo de papel com quatro repetições de 50 sementes a $25^{\circ} \mathrm{C}$ em germinador tipo Mangelsdorf e a interpretação do teste foi efetuado conforme Brasil (1992).

A determinação da porcentagem de embebição de água pelas sementes foi feita conforme Arantes et al. (1994), com quatro repetições de 100 sementes de cada tratamento, que foram pesadas em balança digital e colocadas em copos plásticos com capacidade para $300 \mathrm{ml}$ contendo $70 \mathrm{ml}$ de água deionizada. Em seguida, as sementes foram levadas para uma estufa a $25^{\circ} \mathrm{C}$ por um período de três horas. Retiradas da estufa, foram enxutas em papel-toalha e pesadas para a obtenção do peso final e da porcentagem de embebição de água, seguindo a seguinte fórmula: $\% \mathrm{E}=[(\mathrm{PF}-\mathrm{PI}) / \mathrm{PI}] \mathrm{X} 100$, em que $\% \mathrm{E}=$ porcentagem de embebição, $\mathrm{PF}=$ peso final $\mathrm{da}$ amostra e PI = peso inicial da amostra.

$\mathrm{O}$ teste de germinação foi conduzido com quatro repetições de 50 sementes, sendo as sementes postas para germinar em rolo de papel úmido, num germinador a $25^{\circ} \mathrm{C}$ e em torno de $90 \%$ de umidade relativa, por um período de cinco dias. As avaliações foram realizadas de acordo com as Regras de Análise de Sementes, Brasil, (1992).

$\mathrm{O}$ delineamento experimental utilizado foi $\mathrm{o}$ inteiramente casualizado, em esquema fatorial 9x2 com quatro repetições, sendo o fatorial constituído por nove genótipos de soja e duas épocas de colheita. Os dados obtidos das características avaliadas foram submetidos à análise de variância e comparados pelo teste de Tukey a $5 \%$ de probabilidade.

\section{RESULTADOS E DISCUSSÃO}

No ano agrícola 96/97, houve boa distribuição das precipitações pluviais durante o ciclo da cultura, favorecendo o desenvolvimento das plantas nos estádios vegetativos e reprodutivos. Maiores valores de precipitações foram observados nos meses de dezembro e janeiro, com 195,2 $\mathrm{mm}$ e $348,0 \mathrm{~mm}$, respectivamente. Todas as sementes dos genótipos avaliados receberam chuva próxima ao estádio R8 e após a maturidade fisiológica, sendo mais acentuado naquelas sementes cuja colheita foi realizada no mês de março. Observou-se, por exemplo, no dia 17 de março uma precipitação de 72,4 mm (Figura 1). 
QUADRO 1 - Descrição dos genótipos, datas de semeadura e de colheita das sementes dos nove genótipos estudados. Dourados - MS, 2002.

\begin{tabular}{|l|c|c|cc|}
\hline \multirow{2}{*}{ Genótipos } & \multirow{2}{*}{ Cor do Tegumento } & \multirow{2}{*}{ Data de Semeadura } & \multicolumn{2}{c|}{ Data de Colheita } \\
\cline { 4 - 5 } & & & R8 & Retardamento \\
\hline BRD-9561 & Preto & $30 / 11 / 96$ & $18 / 03$ & $02 / 04$ \\
\hline BRD-9527 & Marrom & $30 / 11 / 96$ & $18 / 03$ & $02 / 04$ \\
\hline BRD-9502 & Amarelo & $30 / 11 / 96$ & $11 / 03$ & $25 / 03$ \\
\hline FT-ABYARA & Amarelo & $30 / 11 / 96$ & $11 / 03$ & $25 / 03$ \\
\hline IAC-100 & Amarelo & $30 / 11 / 96$ & $18 / 03$ & $02 / 04$ \\
\hline BRD-9507 & Amarelo & $30 / 11 / 96$ & $18 / 03$ & $02 / 04$ \\
\hline EMBRAPA-64 & Amarelo & $30 / 11 / 96$ & $11 / 03$ & $25 / 03$ \\
\hline BR-16 & Amarelo & $30 / 11 / 96$ & $11 / 03$ & $25 / 03$ \\
\hline EMBRAPA-4 & Amarelo & $30 / 11 / 96$ & $11 / 03$ & $25 / 03$ \\
\hline
\end{tabular}

\section{R8 - Estádio de maturação R8}

Retardamento - Retardamento de colheita de 14 dias após o estádio R8

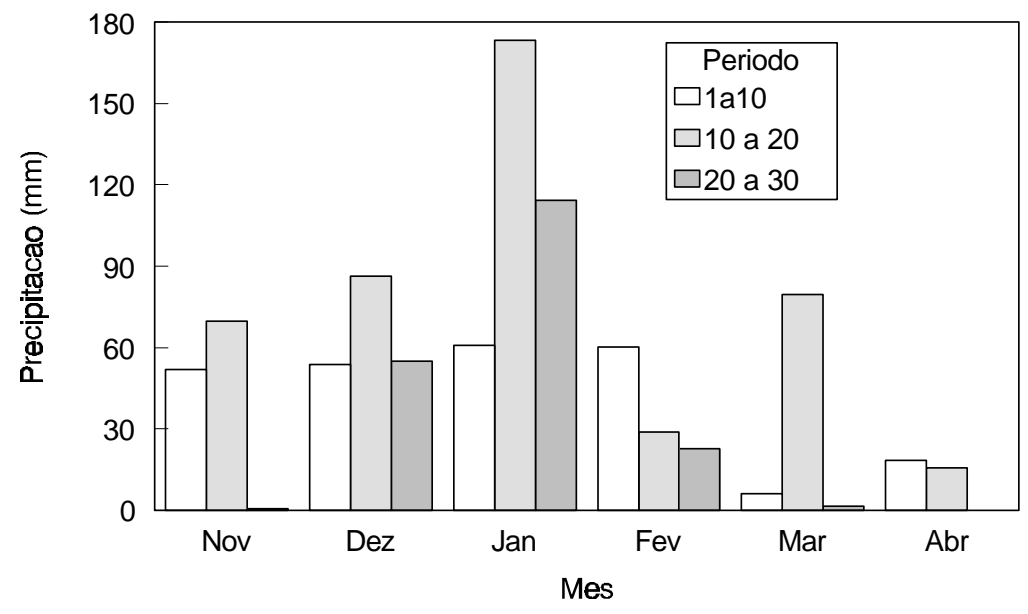

FIGURA 1 - Dados médios por decêndios de precipitação pluviométrica durante a fase de semeadura à colheita, no ano agrícola 96/97. (Dados fornecidos pela Estação Metereológica do Núcleo Experimental de Ciências Agrárias).

As sementes das linhagens tiveram maior espessura de tegumento em relação às cultivares estudadas. Entre os genótipos, sementes da linhagem BRD-9561 com tegumento de coloração preta apresentaram maiores valores de espessura, seguidos pelos observados nas sementes das linhagens BRD-9527 (tegumento mar- rom), BRD-9502 (tegumento amarelo) e BRD-9507 (tegumento amarelo). A menor espessura de tegumento foi verificada nas sementes da cultivar EMBRAPA-4 $(225,090 \mu \mathrm{m})$ e esse valor correspondeu quase à metade da espessura do tegumento da linhagem BRD-9561 (Tabela 1).

Ciênc. agrotec., Lavras. V.27, n.4, p.771-779, jul./ago., 2003 
$\mathrm{Na}$ pesquisa conduzida por Horlings et al. (1991), também foi observada em linhagens com tegumento de coloração preta maior espessura de tegumento em relação a linhagens de tegumento amarelo. Os autores inferem também que a maior espessura de tegumento confere à semente maior resistência às condições adversas durante a sua produção no campo. Por outro lado, Arantes et al. (1994), estudando a espessura de tegumento em 20 cultivares de soja, encontraram maior espessura de tegumento para a cultivar IAC-8 $(222,21$ $\mu \mathrm{m})$ e o menor valor para a linhagem MGBR-22 (81,80 $\mu \mathrm{m})$. As espessuras de tegumento das sementes dessas cultivares foram inferiores aos valores determinados nos nove genótipos de soja estudados (Tabela 1). Segundo Peske et al. (1983), a espessura do tegumento varia entre cultivares. Esses autores observaram ainda que essa característica é constante dentro de cada cultivar, sendo controlada geneticamente e que a mesma parece não ser influenciada pelo local de produção e pelo tamanho da semente.

As sementes da cultivar FT-Abyara colhidas no estádio R8 apresentaram menor porcentagem de embebição de água pelas sementes, não diferindo estatisticamente da linhagem de tegumento marrom BRD-9527 (Tabela 1). No geral, houve aumento da embebição de água pelas sementes com o retardamento de colheita, o que possivelmente pode indicar um aumento de permeabilidade das membranas, provavelmente em decorrência do processo de deterioração das sementes. Rocha et al. (1984) também observaram maior porcentagem de embebição de água em sementes que foram submetidas ao retardamento de colheita.

Segundo Peske e Pereira (1983), sementes com tegumento preto embebem água a uma velocidade menor, quando comparadas com as amarelas, não sendo, portanto, tão prejudicadas pelas condições ambientais na fase de précolheita. Na presente pesquisa, essa situação não pode ser comprovada, pois alguns genótipos contendo sementes com tegumento amarelo tiveram uma porcentagem de embebição de água menor em relação aos de coloração escura, como é o caso da cultivar FT-Abyara, que não diferenciou estatisticamente apenas da linhagem de tegumento marrom BRD-9527, nas duas épocas de colheita.

Como se observa na Tabela 1 , a espessura do tegumento não foi uma característica que determinou a quantidade de água absorvida pelas sementes, pois a linhagem BRD-9561(tegumento preto), com 439,200 $\mu \mathrm{m}$ de espessura de tegumento, teve uma porcentagem de embebição de água pelas sementes maior que a variedade Ft-Abyara com tegumento de $279,990 \mu \mathrm{m}$.

TABELA 1 - Valores médios da espessura do tegumento em $\mu \mathrm{m}$ e da porcentagem de embebição de água de sementes de nove genótipos de soja em função da época de colheita. Dourados - MS, 2002.

\begin{tabular}{|c|c|c|c|}
\hline \multirow{2}{*}{ Genótipos } & \multirow{2}{*}{ Espessura do Tegumento $(\mu \mathrm{m})$} & \multicolumn{2}{|c|}{ Percentagem de Embebição } \\
\hline & & $\mathbf{R 8}$ & Retardamento \\
\hline BRD-9561 & $439,200 \mathrm{a}$ & $62,10 \mathrm{~cd} \mathrm{~B}$ & 85,78 bc $\mathrm{A}$ \\
\hline BRD-9527 & $362,645 \mathrm{~b}$ & 48,90 de $B$ & 79,90 cd A \\
\hline BRD-9502 & $355.940 \mathrm{~b}$ & 88,60 a $A$ & 91,95 bc $\mathrm{A}$ \\
\hline BRD-9507 & $337,940 \mathrm{~b}$ & 92,85 a $\mathrm{B}$ & 118,70 a $A$ \\
\hline FT-Abyara & $279,990 \mathrm{c}$ & 42,15 e $B$ & 67,38 d A \\
\hline IAC-100 & $271,145 \mathrm{~cd}$ & 73,45 bc $\mathrm{B}$ & 85,38 bc A \\
\hline EMBRAPA-64 & $250,405 \mathrm{~cd}$ & $80,55 \mathrm{ab} A$ & 88,85 bc $\mathrm{A}$ \\
\hline BR-16 & $240,650 \mathrm{~cd}$ & 90,03 a $\mathrm{A}$ & 91,68 bc $\mathrm{A}$ \\
\hline EMBRAPA-4 & $225,090 \mathrm{~d}$ & 74,38 bc $\mathrm{B}$ & $95,53 \quad \mathrm{~b} \quad \mathrm{~A}$ \\
\hline C.V.(\%) & 7,18 & \multicolumn{2}{|c|}{7,57} \\
\hline
\end{tabular}

As médias seguidas de mesma letra minúscula nas colunas e maiúscula nas linhas não diferem entre si, pelo teste de Tukey, a $5 \%$ de probabilidade. 
No teste de germinação, as sementes de todos os genótipos colhidas no estádio R8 apresentaram valores de germinação superiores a $80 \%$, com exceção do observado para a cultivar IAC-100. A ocorrência de chuvas próximas à colheita foi possivelmente um dos fatores que mais contribuíram para a deterioração das sementes no campo com o retardamento de colheita, nessa condição houve diferença nos valores de germinação entre os genótipos avaliados. Sementes da linhagem BRD-9502 (tegumento amarelo) e da cultivar EMBRAPA-64 (tegumento amarelo) foram expostas a uma precipitação de aproximadamente $73 \mathrm{~mm}$, próximo à colheita, e mantiveram a germinação acima de $80 \%$, enquanto as cultivares IAC-100, BRD-9507 e EMBRAPA-4 tiveram os valores de germinação reduzidos drasticamente (Tabela 2).

As sementes da linhagem BRD-9527 (tegumento marrom) e da cultivar EMBRAPA-64 apresentaram maior potencial de germinação pelo teste de tetrazólio no estádio $\mathrm{R} 8$. O retardamento da colheita afetou o potencial de germinação das sementes, principalmente das cultivares IAC-100, BR-16 e EMBRAPA-4 (Tabela 2).

Observando-se os valores obtidos para potencial germinação ou viabilidade pelo teste de tetrazólio, ape- nas a linhagem BRD-9507 e a cultivar EMBRAPA-4 apresentaram sementes com germinação inferior a $80 \%$ no estádio R8, e com o retardamento de colheita, a cultivar IAC-100 foi a que teve o potencial de germinação mais reduzido. Vale ressaltar que sementes dessa cultivar apresentaram menores valores de espessura do tegumento, juntamente com os da cultivar EMBRAPA-4. Pode-se afirmar que todos os genótipos diferiram estatisticamente entre si com relação à época de colheita (Tabela 2).

No estádio R8, as sementes das cultivares FTAbyara e EMBRAPA-64 apresentaram maior porcentagem de emergência em areia e a menor emergência foi observada para a linhagem BRD-9507; já no retardamento de colheita, sementes da cultivar IAC-100 apresentaram a menor emergência (Tabela 3). O retardamento de colheita afetou o vigor das sementes e, nessas condições, a cultivar EMBRAPA-64 atingiu porcentagem de emergência das sementes superior a $80 \%$, diferindo significativamente das linhagens BRD-9561, BRD-9502 e BRD-9507, e das cultivares IAC-100 e EMBRAPA-4 (Tabela 3). Esses resultados estão de acordo com os observados por Rocha et al. (1984), em que o retardamento de colheita promoveu decréscimo no total de plântulas emergidas em cada contagem.

TABELA 2 - Valores médios em porcentagem da germinação pelo teste de germinação (TG) e potencial de germinação pelo teste de tetrazólio (PGTZ) de sementes de nove genótipos de soja em função da época de colheita. Dourados - MS, 2002.

\begin{tabular}{|c|c|c|c|c|c|c|}
\hline \multirow{4}{*}{$\begin{array}{r}\text { Genótipos } \\
\text { BRD-9561 }\end{array}$} & \multicolumn{2}{|c|}{ TG } & \multicolumn{4}{|c|}{ PGTZ } \\
\hline & \multicolumn{2}{|c|}{ Época de Colheita } & \multicolumn{4}{|c|}{ Época de Colheita } \\
\hline & $\mathbf{R 8}$ & Retardamento & \multicolumn{2}{|l|}{ R8 } & \multicolumn{2}{|c|}{ Retardamento } \\
\hline & $82 \mathrm{ab} A$ & $75 \mathrm{bc} \quad \mathrm{A}$ & 87 abc & A & 74 a & B \\
\hline BRD-9527 & $83 \mathrm{ab} A$ & $60 \mathrm{de} B$ & 96 a & $\mathrm{A}$ & 78 a & B \\
\hline BRD-9502 & $95 \mathrm{ab} A$ & 91 a $\mathrm{A}$ & $91 \mathrm{ab}$ & A & $77 \mathrm{a}$ & $\mathrm{B}$ \\
\hline BRD-9507 & $81 \mathrm{~b} \quad \mathrm{~A}$ & 50 e $\quad$ B & $74 \mathrm{~d}$ & $\mathrm{~A}$ & $71 \mathrm{ab}$ & B \\
\hline FT- Abyara & $94 \mathrm{a} \quad \mathrm{A}$ & $68 \mathrm{~cd} \mathrm{~B}$ & $90 \mathrm{abc}$ & A & 80 a & $\mathrm{B}$ \\
\hline IAC-100 & $66 \mathrm{c} A$ & $16 \mathrm{f} \quad \mathrm{B}$ & $81 \mathrm{~cd}$ & A & $40 \mathrm{~d}$ & B \\
\hline EMBRAPA-64 & $92 \mathrm{ab} \mathrm{A}$ & $85 \mathrm{ab} A$ & $95 \mathrm{a}$ & A & $77 \mathrm{a}$ & $\mathrm{B}$ \\
\hline BR-16 & 93 a A & 73 bcd B & $83 \mathrm{bcb}$ & A & $61 \mathrm{bc}$ & $\mathrm{B}$ \\
\hline EMBRAPA-4 & $82 \mathrm{ab} A$ & $23 \mathrm{f}$ & $76 \mathrm{~d}$ & $\mathrm{~A}$ & $64 \mathrm{c}$ & $\mathrm{B}$ \\
\hline C.V. $(\%)$ & \multicolumn{2}{|c|}{7,99} & \multicolumn{4}{|c|}{5,74} \\
\hline
\end{tabular}

As médias seguidas da mesma letra minúscula nas colunas e maiúscula nas linhas não diferem entre si pelo teste de Tukey, a $5 \%$ de probabilidade.

Ciênc. agrotec., Lavras. V.27, n.4, p.771-779, jul./ago., 2003 
TABELA 3 - Valores médios de potencial de vigor estimado pelo teste de emergência em areia (\%) de nove genótipos de sementes de soja, em função da época da colheita. Dourados-MS, 2002.

\begin{tabular}{lcc}
\hline \multirow{2}{*}{ Genótipos } & \multicolumn{2}{c}{ Emergência em Areia (\%) } \\
\cline { 2 - 3 } & \multicolumn{2}{c}{ Época de Colheita } \\
\cline { 2 - 3 } & $75 \mathrm{ab} \mathrm{A}$ & Retardamento \\
\hline BRD-9561 & $80 \mathrm{ab} \mathrm{A}$ & $68 \mathrm{ab} \mathrm{A}$ \\
BRD-9527 & $71 \mathrm{~b} \mathrm{~A}$ & $53 \mathrm{bc} \mathrm{B}$ \\
BRD-9502 & $37 \mathrm{c} \mathrm{A}$ & $33 \mathrm{~cd} \mathrm{~A}$ \\
BRD-9507 & $89 \mathrm{a} \mathrm{A}$ & $69 \mathrm{ab} \mathrm{A}$ \\
FT- ABYARA & $40 \mathrm{c} \mathrm{A}$ & $14 \mathrm{~d} \mathrm{~B}$ \\
IAC-100 & $95 \mathrm{a} \mathrm{A}$ & $82 \mathrm{a} \mathrm{A}$ \\
EMBRAPA-64 & $86 \mathrm{ab} \mathrm{A}$ & $72 \mathrm{ab} \mathrm{B}$ \\
BR-16 & $68 \mathrm{~b} \mathrm{~A}$ & $34 \mathrm{~cd} \mathrm{~B}$ \\
EMBRAPA-4 & 15,49 & 15,49 \\
\hline C.V.(\%) &
\end{tabular}

As médias seguidas da mesma letra minúscula nas colunas maiúsculas nas linhas não diferem entre si pelo teste de Tukey a $5 \%$ de probabilidade.
As sementes da linhagem BRD-9502 e da cultivar FT-Abyara, submetidas ao envelhecimento acelerado, apresentaram germinação em torno de $80 \%$, valor considerado alto após o estresse de temperatura e U.R. a que foram submetidas durante o teste, não diferindo estatisticamente da linhagem BRD-9561 e das cultivares EMBRAPA -64 e BR-16, no estádio R8 (Tabela 4).

O retardamento de colheita teve influência marcante naqueles genótipos cujas sementes encontravam-se com vigor mais baixo no estádio $\mathrm{R} 8$, tais como IAC-100, EMBRAPA-4 e a linhagem BRD9507. Isso se deve principalmente ao fato de que a taxa de deterioração das sementes é aumentada consideravelmente pela exposição às condições adversas de temperatura e umidade relativa, e quanto menor for o vigor das sementes, maior será o nível de deterioração quando submetidas a essas condições. As sementes mais vigorosas colhidas na segunda época demonstraram manter sua capacidade de produzir plântulas normais e apresentaram germinação mais elevada após serem submetidas ao envelhecimento acelerado, como a cultivar FT-Abyara e EMBRAPA-64, e as linhagens BRD-9561 e BRD9527(Tabela 4).

TABELA 4 - Valores médios em porcentagem do potencial de vigor estimado pelo teste de tetrazólio (PVTZ) e pelo teste de envelhecimento acelerado (EA) de nove genótipos de sementes de soja, em função da época da colheita. Dourados -MS, 2002.

\begin{tabular}{|c|c|c|c|c|}
\hline \multirow{3}{*}{ Genótipos } & \multicolumn{2}{|c|}{ PVTZ } & \multicolumn{2}{|c|}{ EA } \\
\hline & \multicolumn{2}{|c|}{ Época de Colheita } & \multicolumn{2}{|c|}{ Época de Colheita } \\
\hline & R8 & Retardamento & \multirow{2}{*}{$\begin{array}{c}\mathbf{R 8} \\
73 \mathrm{ab} \mathrm{A}\end{array}$} & \multirow{2}{*}{$\begin{array}{c}\text { Retardamento } \\
61 \mathrm{ab} \mathrm{B}\end{array}$} \\
\hline BRD-9561 & $73 \mathrm{~b} \quad \mathrm{~A}$ & $52 \mathrm{ab} \quad \mathrm{B}$ & & \\
\hline BRD-9527 & $74 \mathrm{ab} \mathrm{A}$ & $50 \mathrm{bc} \quad \mathrm{B}$ & $68 \mathrm{~b} \quad \mathrm{~A}$ & $69 \mathrm{ab} A$ \\
\hline BRD-9502 & $84 \mathrm{a} \quad \mathrm{A}$ & $41 \mathrm{~cd} B$ & 81 a A & 56 bc B \\
\hline BRD-9507 & $32 \mathrm{~d} \mathrm{~A}$ & $13 \mathrm{f} \quad \mathrm{B}$ & $51 \mathrm{c} \quad \mathrm{A}$ & $14 \mathrm{~d} \quad \mathrm{~B}$ \\
\hline FT- ABYARA & $57 \mathrm{c} \quad \mathrm{A}$ & 42 bcd $B$ & $80 \mathrm{ab} A$ & $70 \mathrm{~cd} \mathrm{~B}$ \\
\hline IAC-100 & $34 \mathrm{~d} \quad \mathrm{~A}$ & $8 \mathrm{f} \quad \mathrm{B}$ & $42 \mathrm{~cd} \mathrm{~A}$ & $20 \mathrm{~cd} \mathrm{~A}$ \\
\hline EMBRAPA-64 & $83 \mathrm{ab} A$ & $62 \mathrm{a}$ & $77 \mathrm{ab} A$ & 70 a A \\
\hline BR-16 & $61 \mathrm{c} \mathrm{A}$ & $29 \mathrm{e}$ & $73 \mathrm{ab} A$ & 33 c $B$ \\
\hline EMBRAPA-4 & $60 \mathrm{c} \mathrm{A}$ & $34 \mathrm{de}$ & $29 \mathrm{~d} \quad \mathrm{~A}$ & $24 \mathrm{~cd} \mathrm{~A}$ \\
\hline C.V.(\%) & 8.81 & 8.81 & 15,49 & 15,49 \\
\hline
\end{tabular}

As médias seguidas da mesma letra minúscula nas colunas e maiúsculas nas linhas não diferem entre si pelo teste de Tukey a $5 \%$ de probabilidade. 
$O$ vigor das sementes estimado pelo teste de tetrazólio foi influenciado pela época de colheita e pelos genótipos (Tabela 4). As sementes da linhagem BRD9502 e da cultivar EMBRAPA-64 colhidas no estádio $\mathrm{R} 8$ foram as mais vigorosas, seguidas das linhagens BRD-9561 e BRD-9527, diferindo significativamente dos demais materiais. De acordo com os resultados do teste de tetrazólio, as maiores porcentagens de vigor foram obtidas quando a colheita foi realizada no estádio $\mathrm{R} 8$, e o atraso da colheita levou a uma redução do vigor e a taxa de redução foi diferente entre os genótipos estudados, como pode ser observado na Tabela 4.

Pode-se inferir que as sementes das linhagens BRD-9561 e BRD-9527, e da cultivar EMBRAPA64 , tiveram menor perda de vigor com o retardamento da colheita, enquanto as da linhagem BRD9507 e da cultivar IAC-100 apresentaram redução acentuada no vigor das sementes nas duas épocas de colheita (Tabela 4).

Após efetuado o teste de correlação entre a espessura de tegumento de cada genótipo avaliado e os testes realizados para determinar a viabilidade e o vigor das sementes (dados não apresentados), não foi observada uma associação entre a espessura do tegumento e a qualidade fisiológica de sementes de soja.. Apesar de as linhagens apresentarem maior espessura de tegumento, não se observou uma correlação significativa dessa característica com os parâmetros de avaliação da qualidade fisiológica de sementes de soja.

\section{CONCLUSÕES}

a) A espessura do tegumento é uma característica que per si não assegura uma melhor qualidade fisiológica das sementes, independente da época de colheita;

b) O retardamento de colheita aumenta a porcentagem de embebição de água pelas sementes e reduz a porcentagem de germinação e vigor dessas, independente da espessura do tegumento.

\section{REFERÊNCIAS BIBLIOGRÁFICAS}

ARANTES, H. A. G.; ROCHA, V. S.; SILVA, E. A. M.; SEJIYAMA, T. Espessura do tegumento, embebição em água e qualidade fisiológica da semente de soja. Revista Ceres, Viçosa, v. 41, n. 234, p. 126-132, 1994.

BRASIL. Ministério da Agricultura. Regras para análise de sementes. Brasília, 1992. 365 p.
COSTA, N. P.; FRANÇA NETO, J. de B.; KRZYZANOWISKI, F. C.; PARO, H.; MENDES, M. C. Diagnóstico da qualidade de sementes de soja produzidas no Estado de Mato Grosso. Arquivos de Biologia e Tecnologia, Curitiba, v. 38, n. 2, p. 565-583, 1995.

DASSOU, S.; KUENEMAN, E. A. Screening methodology for resistance to field weathering in soybean seed. Crop Science, Madison, v. 24, p. 774-778, 1984.

FRANÇA NETO, J. B.; PEREIRA, L. A. G.; COSTA, N. P.; KRZYZANOWISKI, F. C.; HENNING, A. A. Metodologia do teste de tetrazólio em sementes de soja. Londrina: EMBRAPA-CNPSo, 1994. 59 p.

FRANÇA NETO, J. B.; KRZYZANOWSKI, F. C.; WEST, S. H.; HENNING, A. A.; COSTA, N. P. Determinação do conteúdo de liguinina nos tegumentos de sementes de soja com tegumento preto e amarelo. In: REUNIÃO DE PESQUISA DE SOJA DA REGIÃO CENTRAL DO BRASIL, 21., 1999, Londrina. Anais... Londrina: Embrapa soja, 1999. 247 p. (Embrapa Agropecuária Oeste. Documentos, 7; Embrapa Soja. Documentos, 134).

HORLINGS, G. P.; GAMBLE, E. E.; SHAMMUG, S. $S$. The influence of seed size and seed coat characteristics on seed quality of soybean in the tropics. Field Weathering Seed Science and Technology, [S.1.], v. 19, p. 665-685, 1991.

MARCOS FILHO, J.; CÍCERO, S. M.; SILVA, W. R. Avaliação da qualidade das sementes. Piracicaba: FEALQ, 1987. 230 p.

PESKE, S.; PEREIRA, L. A. G. Tegumento da semente de soja. Tecnologia de Sementes, Pelotas, v. 6, n. 1/2, p. 23-24, 1983.

ROCHA, V. S.; SEDIYAMA, T.; SILVA, R. F. da; SEDIYAMA, C. S.; THIEBAUT, J. T. L. Embebição de água e qualidade fisiológica de sementes de soja. Revista Brasileira de Sementes, Brasília, ano 6, n. 2, 1984.

SEDIYAMA, T.; SILVA, R. F.; THIÉBAUT, J. T. L.; REIS, M. S.; FONTES, L. A. N.; MARTINS, O. Influência da época de semeadura e do retardamento da colheita sobre a qualidade das sementes e outras características agronômicas das variedades de soja UFV-1 e UFV-2, em Capinópolis, MG. In: SEMINÁRIO NACIONAL DE

Ciênc. agrotec., Lavras. V.27, n.4, p.771-779, jul./ago., 2003 
PESQUISA DE SOJA, 2., 1981, Capinópolis. Anais... Capinópolis: EMBRAPA, 1981. v. 1, p. 645-659.

TAVARES, D. Q.; MIRANDA, M. A. C.; UMINO, C. Y.; DIAS, G. M. Características estruturais do tegumento de sementes permeáveis e impermeáveis de linhagens de soja. Revista Brasileira de Botânica, São Paulo, v. 10, p. 147-153, 1987.
VIEIRA, R. D.; SEDIYAMA, T.; SILVA, R. F.; SEDIYAMA, C. S.; THIÉBAUT, J. R. L.; XIMENES, P. A. Estudo da qualidade fisiológica de sementes de soja, cultivar UFV-1, em quinze épocas de colheita. In: SEMINÁRIO NACIONAL DE PESQUISA DE SOJA, 2., Capinópolis. Anais... Capinópolis: EMBRAPA, 1981. v. 1, p. 633634. 